\title{
Serum proteomic profiling in patients with drug-induced liver injury
}

\author{
L. N. Bell ${ }^{\star}$, R. Vuppalanchi ${ }^{\star}$, P. B. Watkins ${ }^{\dagger}$, H. L. Bonkovsky ${ }^{\dagger} \neq, \S$, J. Serranoף, R. J. \\ Fontana $^{* *}$, M. Wang ${ }^{\dagger \dagger}$, J. Rochon ${ }^{\ddagger \ddagger}$, and N. Chalasani ${ }^{*}$ for the US Drug-Induced Liver Injury \\ Network (DILIN) Research Group \\ "Division of Gastroenterology/Hepatology, Indiana University, Indianapolis, IN, USA. \\ tDepartment of Internal Medicine, University of North Carolina at Hill, Chapel Hill, NC, USA. \\ $\ddagger$ Cannon Research Center and Center for Liver and Digestive Diseases, Carolinas Medical \\ Center, Charlotte, NC, USA. \\ $\S$ Department of Internal Medicine, University of Connecticut, Farmington, CT, USA. \\ "Liver Disease Research Branch, NIH/NIDDK, Bethesda, MD, USA. \\ ${ }^{* *}$ Department of Internal Medicine, University of Michigan, Ann Arbor, MI, USA. \\ t+Protein Analysis Research Center, Indiana University, Indianapolis, IN, USA. \\ ¥¥Duke Clinical Research Institute, Durham, NC, USA.
}

\section{SUMMARY}

Background-Idiosyncratic drug-induced liver injury (DILI) is a complex disorder that is difficult to predict, diagnose and treat.

\begin{abstract}
Aim-To describe the global serum proteome of patients with DILI and controls.
Methods-A label-free, mass spectrometry-based quantitative proteomic approach was used to explore protein expression in serum samples from 74 DILI patients (collected within 14 days of DILI onset) and 40 controls. A longitudinal analysis was conducted in a subset of 21 DILI patients with available 6-month follow-up serum samples.
\end{abstract}

\begin{abstract}
Results-Comparison of DILI patients based on pattern, severity and causality assessment of liver injury revealed many differentially expressed priority 1 proteins among groups. Expression of fumarylacetoacetase was correlated with alanine aminotransferase (ALT; $r=0.237 ; P=0.047$ ), aspartate aminotransferase (AST; $r=0.389 ; P=0.001)$ and alkaline phosphatase $(r=-0.240 ; P=$ 0.043 ), and this was the only protein with significant differential expression when comparing patients with hepatocellular vs. cholestatic or mixed injury. In the longitudinal analysis, expression of 53 priority 1 proteins changed significantly from onset of DILI to 6-month follow-up, and nearly all proteins returned to expression levels comparable to control subjects. Ninety-two serum priority 1 proteins with significant differential expression were identified when comparing the
\end{abstract}

\section{(C) 2012 Blackwell Publishing Ltd}

Correspondence to: Dr N. Chalasani, Division of Gastroenterology/Hepatology, Indiana University School of Medicine, 1050 Wishard Blvd., RG 4100, Indianapolis, IN 46202, USA. nchalasa@iupui.edu.

Declaration of personal interests: Drs Bonkovsky, Watkins and Chalasani have financial consulting agreements with several pharmaceutical companies, but no one poses a potential conflict relevant to the current study.

SUPPORTING INFORMATION Additional Supporting Information may be found in the online version of this article:

Please note: Wiley-Blackwell are not responsible for the content or functionality of any supporting materials supplied by the authors. Any queries (other than missing material) should be directed to the corresponding author for the article. 
DILI and control groups. Pattern analysis revealed proteins that are components of inflammation, immune system activation and several hepatotoxicity-specific pathways. Apolipoprotein E expression had the greatest power to differentiate DILI patients from controls (89\% correct classification; AUROC $=0.97$ ).

Conclusion-This proteomic analysis identified differentially expressed proteins that are components of pathways previously implicated in the pathogenesis of idiosyncratic drug-induced liver injury.

\section{INTRODUCTION}

Although relatively rare with the majority of approved medications, idiosyncratic druginduced liver injury (DILI) is an increasingly common event due to ever-expanding use of prescription medications. DILI is the most frequent adverse drug reaction that results in termination of new drug development programmes, failure of approval by regulatory agencies, or withdrawal of approved medications. ${ }^{1-4}$ When idiosyncratic DILI does occur it can be a serious clinical event and, in fact, accounts for up to $13 \%$ of acute liver failure cases in the United States. ${ }^{5-7}$ Despite the large impact DILI has on both patient health and the development of important new medications, there is little understanding of the risk factors and pathogenesis of idiosyncratic ADRs that result in liver injury. ${ }^{8,9}$ This lack of understanding has prevented development of new clinical tests that are needed to aid in diagnosis and management of DILI.

Worldwide, several multicenter networks have been established to aid in the study of identification, causes and prevention of idiosyncratic DILI. In the United States, the DrugInduced Liver Injury Network (DILIN) was founded in 2003 as a collaborative effort among the National Institutes of Health, eight academic clinical centres, and a data coordinating centre. ${ }^{10}$ One component is the DILIN Prospective Study, which is a prospective observational study of patients with suspected DILI. This study is described in several publications reporting study design, ${ }^{10}$ causality assessment,${ }^{11}$ implicated medications, clinical features and outcomes for the first 300 enrolled patients, ${ }^{12}$ and clinical characteristics of drug-specific hepatotoxicity. ${ }^{13,14}$

Here, we utilised a label-free quantitative proteomics approach (LFQP) to profile global protein expression in serum samples from patients with idiosyncratic DILI enrolled in the DILIN prospective study and healthy control subjects. LFQP is a high-throughput, sensitive method for quantification of thousands of proteins in complex biological samples, including serum. ${ }^{15}$ The objectives of this study were to: (i) describe differences in serum protein expression among DILI patients based on hepatocellular, cholestatic, or mixed pattern of liver injury, severity of liver injury (mild, moderate or severe/fatal), and causality assessment (definite, very likely, probable, possible or unlikely), (ii) explore longitudinal changes in serum protein expression over a 6-month recovery period in a subset of DILI patients, (iii) identify differentially expressed serum proteins among patients with DILI vs. controls, (iv) identify potential protein biomarkers of DILI with high discriminate ability and (v) compare differentially expressed proteins identified in the current DILI study to those identified in our previous serum proteomic analysis of patients across the spectrum of nonalcoholic fatty liver disease (NAFLD). ${ }^{16}$

\section{MATERIALS AND METHODS}

Serum samples were obtained from a local blood bank (healthy controls) or were collected as part of the DILIN prospective study, which was approved by the Institutional Review Board at each academic clinical centre. As described, ${ }^{10}$ eligible patients with suspected DILI provided written informed consent prior to their baseline study visit in which all previous 
medical data was reviewed with regard to inclusion/exclusion criteria and a complete history and physical examination were performed. Patients were then enrolled if there was strong suspicion that liver injury was caused by a prescription or over-the-counter medication or dietary supplement/herbal product within the previous 6 months. Further laboratory testing and data collection were also undertaken to fully characterise the DILI event and to exclude underlying or competing aetiologies. All surviving participants were invited to return for a 6-month follow-up visit.

\section{Inclusion/exclusion criteria}

Eligibility for the DILIN prospective study included $>2$ years of age, a date of DILI onset within the 6 months prior to enrolment and satisfaction of at least one of the following biochemical criteria: (i) serum alanine aminotransferase (ALT) or aspartate aminotransferase $($ AST) $>5$ times the upper limit of normal (ULN) or alkaline phosphatase $>2$ times the ULN (or increases above pre-treatment baselines if liver biochemistries were elevated prior to starting drug) on two consecutive occasions at least 2 days apart, (ii) total serum bilirubin $>2.5 \mathrm{mg} / \mathrm{dL}$ together with elevated AST, ALT or alkaline phosphatase or (iii) international normalised ratio (INR) $>1.5$ together with elevated AST, ALT or alkaline phosphatase. Patients with pre-existing liver conditions who developed superimposed DILI were included. Patients with known or suspected acetaminophen toxicity or prior liver or bone marrow transplant were excluded.

\section{Clinical characterization of DILI and causality assessment}

Type of liver injury was characterised by the $\mathrm{R}$ ratio $[\mathrm{R}=(\mathrm{ALT} / \mathrm{ULN}) /($ alkaline phosphatase/ULN) $]^{1,2}$ : (i) $\mathrm{R} \geq 5$ was characterised as hepatocellular DILI, (ii) $\mathrm{R} \leq 2$ was characterised as cholestatic DILI and (iii) $\mathrm{R}>2$ to $\mathrm{R}<5$ was characterised as mixed DILI. As previously described, ${ }^{10}$ severity of DILI was graded as: (i) mild, (ii) moderate, (iii) moderate-hospitalised, (iv) severe or (v) fatal. For the purposes of this study, patients with moderate or moderate-hospitalised DILI were combined (moderate DILI) and patients with severe or fatal DILI were combined (severe/fatal DILI). Causality was assessed by two different methods as previously described ${ }^{10-12}$ : (i) the Roussel Uclaf Causality Assessment Method (RUCAM) and (ii) assignment of DILIN causality score based on unanimous consensus of at least three DILIN Causality Committee members. Final causality was categorised as: (i) definite (>95\% likelihood), (ii) very likely (75-95\%), (iii) probable (50$74 \%)$, (iv) possible $(25-49 \%)$ or (v) unlikely $(<25 \%)$.

\section{Sample preparation}

All proteomic analyses were performed by the Protein Analysis Research Centre at Indiana University School of Medicine. As previously described, ${ }^{15}$ samples were treated with protease inhibitor cocktail (Sigma Aldrich, St. Louis, MO, USA) and protein extraction from $<100 \mu \mathrm{L}$ serum was carried out in lysis buffer containing $8 \mathrm{~m}$ urea and $10 \mathrm{~m}_{\mathrm{M}}$ dithiothreitol (DTT). Fourteen high-abundance proteins were depleted by SepproTip columns (albumin, IgG, alpha-1-antitrypsin, IgA, IgM, transferrin, haptoglobin, alpha-2-macroglobulin, fibrinogen, complement C3, alpha-1-acid glycoprotein and apolipoproteins A-1, A-II and B) and Bradford assay was used to determine protein concentrations. ${ }^{17}$ DTT, iodoacetamide, triethylphosphine and iodoethanol were used to reduce and alkylate resulting protein extracts. ${ }^{18}$ Protein mixtures were digested with trypsin and filtered through spin filters before being applied to the high-performance liquid chromatography (HPLC) system. Stability of the HPLC system and mass spectrometry (MS) instrument was evaluated by spiking a constant amount of chicken lysozyme as an internal reference prior to tryptic digestion of protein extracts. 


\section{Liquid chromatography-tandem mass spectrometry (LC/MS/MS)}

In random order, peptides $(<20 \mu \mathrm{g})$ were injected onto an Agilent 1100 nano-HPLC system (Agilent Technologies, Inc., Santa Clara, CA, USA) equipped with a C18 capillary column. Peptides were eluted with a linear gradient from 5\% to $45 \%$ acetonitrile developed at a flow rate of $500 \mathrm{~nL} / \mathrm{min}$ over $120 \mathrm{~min}$. Effluent was electrosprayed into a LTQ mass spectrometer (Thermo Fisher Scientific, Inc., Waltham, MA, USA). Acquired data were filtered and analysed by a proprietary algorithm ${ }^{19}$ and database searches were carried out using the $\mathrm{X}$ ! Tandem ${ }^{20}$ and SEQUEST ${ }^{21}$ algorithms against the International Protein Index (IPI) human database (European Bioinformatics Institute, version 3.60) as previously described. ${ }^{22}$

\section{Protein identification and quantification}

Proteins were classified as priority one through four according to quality of peptide identification (ID). ID confidence for each protein is greater with: (i) higher ID confidence of individual peptides and (ii) a greater number of distinct amino acid sequences identified. Priority 1 proteins have the greatest likelihood of correct identification (with multiple unique peptide sequences identified) and priority 4 proteins have the least likelihood of correct identification.

Quantification of proteins was carried out as previously described. ${ }^{19}$ Briefly, raw data files were acquired from the MS instrument and all chromatograms were aligned according to their retention time. After alignment, the area-under-the-curve for each individually aligned peak was measured, normalised and compared for relative abundance.

\section{Biostatistical analysis}

Significant changes in protein expression among groups were detected by ANova (analysis of variance). All data were normalised on a $\log _{2}$ scale (one unit difference is equivalent to a two-fold change). ${ }^{23}$

From the anova model a $P$-value, an estimate of the FPR (false positive rate), was obtained. The $P$-value was modified to a $q$-value, which estimates the FDR (false discovery rate). The $q$-value threshold was fixed to control the FDR at 5\% $(<0.05)$. A protein with 'significant change' or 'differential expression' was defined as a difference in protein expression between any two groups with a $q$-value $<0.05$.

\section{Pathway and additional statistical analyses}

For the main analysis and all subgroup analyses, all priority 1 proteins with significant differential expression $(q<0.05)$ were considered for further characterization. Identified proteins were classified according to biological function(s) using Ingenuity Pathway Analysis software (https://analysis.ingenuity.com). Pearson's correlation coefficient was used to detect associations between liver biochemistries and expression of priority 1 proteins. When appropriate, stepwise regression analysis was performed to take into account multiple independent variables (proteins) predicting the dependent variable (liver biochemistries). Linear discriminant analysis and area-under-the-receiver-operating-curve (AUROC) was used to determine the ability of individual proteins differentially expressed between groups and patient characteristics to predict the presence of DILI vs. controls. Statistical analyses were performed using JMP software (SAS Institute, Inc., Cary, NC, USA). A $P$-value $<0.05$ was considered significant. 


\section{RESULTS}

\section{Patient characteristics}

A total of 114 subjects were included in this serum proteomic study. Characteristics of the 74 DILI patients (with a serum sample collected within 14 days of DILI onset) and 40 control subjects, including demographics and liver biochemistries, are shown in Table 1. Implicated agents, regardless of causality assessment, are listed in Table 2. Overall, 2671 proteins were identified with the criteria we set for $\mathrm{LFQP}^{19,22}: 217$ priority 1 proteins, 734 priority 2 proteins, 182 priority 3 proteins and 1538 priority 4 proteins.

In the DILI cohort, correlations between expression of differentially expressed priority 1 proteins and liver biochemistries were explored (Table 3). Interestingly, expression of fumarylacetoacetase, an enzyme required for the breakdown of tyrosine, was associated with ALT $(r=0.237 ; P=0.047)$, AST $(r=0.389 ; P=0.001)$ and alkaline phosphatase $(r=$ $-0.240 ; P=0.043)$. Fructose-bisphosphate aldolase $\mathrm{B}$, a protein involved in carbohydrate metabolism, was identified as an independent predictor of both ALT $(r=0.391 ; P=0.001)$ and AST $(r=0.523 ; P<0.001)$. Apolipoproteins C-III (component of VLDL) and A-II (component of HDL) were independently associated with alkaline phosphatase $(r=0.275 ; P$ $=0.014)$ and bilirubin $(r=-0.225 ; P=0.05)$ levels respectively. Additional independent predictors of bilirubin included proteins involved in extracellular matrix structure [extracellular matrix protein 1 (isoform 1) $(r=0.229 ; P=0.024)$ ], iron metabolism and antioxidant function [hemopexin $(r=0.494 ; P<0.001)$ ], and post-translational protein modification [E3 SUMO-protein ligase RanBP2 $(r=0.265 ; P=0.024)$ ].

\section{Pattern analysis: comparison of hepatocellular, cholestatic, or mixed liver injury}

Within the DILI cohort, 45 patients (61\%) were classified as having hepatocellular DILI, 15 patients (20\%) hadcholestatic DILI, 11 patients (15\%) had mixed DILI and three patients (4\%) were not classified by DILI type and were therefore not included in the pattern analysis. We identified 25 differentially expressed $(q<0.05)$ proteins when comparing patients with hepatocellular and cholestatic patterns of DILI (listed in Supplementary Table S1). Expression of only one protein, fumarylacetoacetase, was different among patients with hepatocellular and mixed DILI, and there were no differentially expressed proteins when comparing the cholestatic and mixed DILI groups. Pattern analysis of the 25 priority 1 proteins differentially expressed between hepatocellular and cholestatic DILI patterns showed involvement in mechanistic pathways implicated in DILI, including hepatotoxicityspecific mechanisms of liver proliferation and development of cirrhosis (Figure 1).

\section{Severity analysis: comparison of mild, moderate or severe/fatal liver injury}

Mild $(n=9 ; 12 \%)$, moderate $(n=35 ; 47 \%)$ and severe/fatal $(n=19 ; 26 \%)$ DILI were all well-represented in our cohort. Severity of DILI was not reported for 11 patients (15\%), and these subjects were excluded from this severity analysis. As shown in Supplementary Table S2, expression of 29 priority 1 proteins was significantly different $(q<0.05)$ between the mild and moderate DILI groups, 52 priority 1 proteins were differentially expressed between the mild and severe/fatal DILI patients, and comparison of the moderate vs. severe/fatal DILI groups revealed 23 priority 1 proteins with significant differential expression. Expression of 9 priority 1 proteins was significantly different when comparing all three severity groups: obscurin (isoform 1), polymeric immunoglobulin receptor, serine/threonineprotein kinase 10, apolipoprotein A-II, transthyretin, macrophage colony-stimulating factor 1 receptor, complement component C7, vitamin D-binding protein and vitamin D-binding protein precursor. Pattern analysis of these nine common proteins revealed involvement in the acute phase response, activation of the complement cascade and peroxisome proliferator- 
activated receptor (PPAR)- $a$, and association with development of hepatocellular carcinoma.

\section{Causality assessment analysis: comparison of definite, very likely, probable, possible or unlikely DILI}

In our cohort of DILI patients, 17 were adjudicated as definite DILI (23\%), 27 as very likely DILI (36\%), 8 as probable DILI (11\%) and 11 as possible DILI (15\%). Causality assessment was not completed in seven cases (9\%), and those patients were excluded from this causality assessment analysis. Significant differential expression of priority 1 proteins was only observed when comparing the definite and possible DILI groups (list of 12 proteins is shown in Supplementary Table S3). Four subjects were deemed unlikely to have DILI and were therefore classified as an 'acute liver disease group.' When these four patients were compared with patients with DILI, no differentially expressed priority 1 proteins were identified.

\section{Longitudinal DILI analysis}

Serum samples obtained within 14 days of DILI onset and after a 6-month follow-up period were available for a subset of patients ( $n=21 ; 28 \%$ of the DILI cohort), and clinical characteristics and liver biochemistries of these patients are shown in Table 4. Expression of 53 priority 1 proteins changed significantly $(q<0.05)$ over the 6-month follow-up period (Supplementary Table S4), and nearly all proteins trended back towards a 'normal' expression level (utilising the control group as a reference standard). As shown in Figure 2, pathway analysis of these 53 proteins again revealed involvement in host immune response, oxidative stress and hepatotoxicity-specific pathways including liver inflammation, steatosis/steatohepatitis, necrosis/cell death and hepatitis.

\section{Comparison of DILI patients and controls}

Ninety-two priority 1 proteins were found to be differentially expressed $(q<0.05)$ between the DILI and control groups (described in Supplementary Table S5). Pattern analysis of these proteins revealed components of several mechanistic pathways, including inflammation, acute phase proteins, complement system activation and coagulation (Figure 3; Panel A). In addition, several pathways directly related to hepatotoxicity (hepatic inflammation, steatosis, cholestasis, necrosis/cell death and hepatitis) were represented in the pattern analysis.

We assessed the ability of all priority 1 proteins differentially expressed between DILI patients and controls $(n=92)$, along with patient characteristics (BMI and age) and liver biochemistries (ALT, AST, alkaline phosphatase and bilirubin), to predict the presence of DILI. As shown in Figure 3 (Panel B), apolipoprotein E had the greatest diagnostic ability $(89 \%$ of patients classified correctly; AUROC $=0.97)$ to distinguish DILI samples from controls. When inter-alpha-trypsin inhibitor (heavy chain $\mathrm{H} 3$, isoform 1) was added, correct patient classification increased to $91 \%$ (AUROC $=0.98$ ). Addition of gelsolin $(92 \%$ correct classification; AUROC $=0.99)$ followed by complement component C7 (93\% correct classification; AUROC $=0.99$ ), serum amyloid $\mathrm{P}$ component $(95 \%$ correct classification; AUROC $=0.99)$ and age $(96 \%$ correct classification; AUROC $=0.99)$ all increased the ability to predict DILI. The ability of ALT $(73 \%$ correct classification; AUROC $=0.99)$ (Figure 3; Panel B), AST (67\% correct classification; AUROC $=0.99$ ), alkaline phosphatase (68\% correct classification; AUROC $=0.96)$, bilirubin $(77 \%$ correct classification; AUROC $=0.94)$ or all four liver biochemistries combined $(81 \%$ correct classification; AUROC $=$ 0.99 ) to correctly classify patients with DILI vs. controls was also explored. 


\section{Comparison with NAFLD proteomics}

To identify potential nonspecific serum biomarkers of liver injury, we assessed overlap of differentially expressed priority 1 proteins identified in both the present study of DILI patients and healthy controls (92 priority 1 proteins) and in our previous serum proteomic study of patients across the spectrum of NAFLD and obese controls (56 priority 1 proteins). ${ }^{16}$ Twenty-seven priority 1 proteins exhibited significant differential expression ( $q$ $<0.05$ ) compared with the respective control groups in both the DILI and NAFLD analyses, and these proteins and their direction of change are listed in Supplementary Table S6.

\section{DISCUSSION}

There is an important need for increased understanding of the pathogenesis of DILI in humans. Here, we describe results from a comprehensive serum proteomic analysis of patients with DILI and controls. We observed significant differential expression of serum proteins when comparing patients within the DILI group based on disease pattern, severity and causality assessment and identified numerous differentially expressed proteins between DILI patients and controls. In addition, strong associations between expression levels of many priority 1 proteins and liver biochemistries were detected and 53 serum proteins that changed significantly over a 6-month recovery period were identified. Pattern analysis of differentially expressed proteins confirmed changes in protein expression related to mechanistic pathways previously implicated in the pathogenesis of DILI, including inflammatory and acute phase response, complement and coagulation system activation, and oxidative stress. ${ }^{9,} 24$ In addition, proteins included in several hepatotoxicity-specific pathways were identified, including liver inflammation, proliferation, steatosis/ steatohepatitis/hepatitis, cirrhosis, hepatocellular carcinoma and hepatocyte necrosis/death.

Large-scale '-omics' technologies are powerful tools for molecular profiling of complex disorders such as idi-osyncratic DILI. Conducted primarily in animal models of DILI, various proteomic studies, often supplemented with metabonomic and transcriptomic analyses, have revealed important information regarding prediction, detection, pathogenesis and treatment of both acetaminophen-induced and idiosyncratic DILI. ${ }^{25-39}$ Of particular relevance to the current proteomic study is a report by Andersson et al. describing metabolomic and proteomic changes in serum samples from patients treated with ximelagatran, which was associated with acute liver failure and was withdrawn from the market in 2006. ${ }^{30}$ Novel biomarkers to predict predisposition to ALT elevation and treatment response to ximelagatran were identified, including apolipoproteins A-II, A-IV and $\mathrm{E}$, and subsequent hypothesis-driven in vitro studies were carried out to confirm previously unknown mechanisms of toxicity. In addition, Lewis et al. utilised an innovative in vitro model system combined with a proteomic approach to identify intracellular and extracellular proteins secreted into culture medium by a human hepatoma-derived cell line (Hep G2/C3A) in response to ethanol toxicity. ${ }^{27}$ Interestingly, several differentially expressed proteins identified in this model system were also detected in the current serum proteomic study, including fructose-bisphosphate aldolase A, apolipoproteins A-I and E, and multiple proteins involved in acute phase and inflammatory responses.

In the current study, interesting associations between expression of several identified serum proteins and liver biochemistries were observed. For example, fumarylacetoacetase, an enzyme predominantly expressed in the liver that is essential for tyrosine metabolism, was significantly elevated in DILI patients compared with controls, correlated with ALT, AST and alkaline phosphatase, and was also identified as the only priority 1 protein with significantly higher expression in patients with hepatocellular vs. mixed pattern of injury. Type I tyrosinaemia, a genetic disorder characterised by fumarylacetoacetase deficiency and systemic accumulation of tyrosine, is strongly associated with liver failure and 
hepatocellular carcinoma. ${ }^{40}$ Indeed, the significant upregulation of fumarylacetoacetase expression in patients with hepatocellular DILI suggests a compensatory mechanism in response to accumulation of tyrosine and/or other toxic metabolites, including fumarylacetoacetate, induced by hepatotoxic agents. Fructose-bisphosphate aldolase B, a hepatic enzyme involved in glucose and fructose metabolism, was significantly greater in patients with DILI compared with controls and in patients with hepatocellular DILI vs. cholestatic DILI, and was identified as an independent correlate of both serum ALT and AST elevations. Furthermore, fructose-bisphosphate aldolase B expression was significantly elevated at baseline and expression returned to normal levels after 6 months in the longitudinal analysis. These associations may provide an explanation for the previously demonstrated detection of serum autoantibodies to fructose-bisphosphate aldolase B in patients with troglitazone-induced hepatotoxicity ${ }^{41}$ and support the concept that expression levels of this enzyme may correlate with extent of liver injury.

Identification of useful, noninvasive biomarkers of idiosyncratic DILI is complicated by the fact that animal studies predict only approximately $50 \%$ of drugs that ultimately cause hepatotoxicity in humans, and in vitro hepatocyte testing identifies 50-60\% of compounds that can induce liver injury in human clinical trials. ${ }^{42}$ In this serum proteomic study, we identified elevations in apolipoprotein $\mathrm{E}$, an abundant apolipoprotein constituent of triglyceride-rich chylomicrons and intermediate-density lipoproteins, as having the greatest diagnostic power for differentiating patients with DILI from controls. Interestingly, Ferre et al. demonstrated that apolipoprotein E-deficient mice exhibited worse liver injury upon carbon tetrachloride challenge compared with wild-type mice. ${ }^{43}$ Inclusion of expression of additional proteins involved in inflammation [inter-alpha-trypsin inhibitor (heavy chain H3, isoform 1) and serum amyloid P-component], mitochondrial stabilisation and apoptosis (gelsolin), and the innate immune response (complement component C7 and serum amyloid P-component) increased our ability to predict the presence of DILI. These findings are consistent with the response of hepatocytes and other cell types residing in the liver to druginduced injury, which involves systemic release of cytokines and other factors implicated in various inflammatory and immunity pathways. ${ }^{24}$

Although this study was the first to explore the global serum proteome of patients with idiosyncratic DILI, there are several limitations that require mention. First, although distinguishing DILI patients from healthy control subjects is interesting from a pathogenetic stand-point, this approach is not highly relevant in a clinical setting. Rather, identification of biomarkers for rapid differentiation of patients with DILI from those with other acute liver diseases is an important unmet clinical need. We were unable to assess this issue as the current study included only a small group of patients with acute liver injury thought unlikely to be due to DILI $(n=4)$. Second, a concern with multiple serum proteomic studies involving different liver diseases is the possibility of identification of nonspecific markers of hepatic injury. We compared findings from the current proteomic study in DILI patients and healthy controls to data generated from our previous discovery proteomic study in patients across the spectrum of NAFLD and obese controls. ${ }^{16}$ Of the 92 and 56 differentially expressed priority 1 proteins identified in the DILI and NAFLD analyses respectively, only 27 common proteins were identified and may serve as general biomarkers of liver injury. Importantly, apolipoprotein E, which was identified as having the greatest ability to differentiate DILI patients from controls, was not differentially expressed in the NAFLD proteomic analyses. This protein, along with the additional 65 proteins with significant differential expression unique to the DILI analysis, may serve as candidate biomarkers for identification of DILI. Third, we were unable to assess changes in serum protein expression with regard to individual medications/supplements due to the large number of agents and small numbers of patients exposed to individual drugs. Finally, prediction of individuals who will go on to develop hepatotoxicity prior to drug exposure would be an invaluable tool 
for drug development and improved patient safety. This type of analysis requires serum samples taken prior to DILI onset, which are not available as part of the DILIN prospective registry. Despite these limitations, our study provides novel insight into changes in the serum proteome in patients with idiosyncratic drug-induced hepatotoxicity and provides a foundation for future hypothesis-driven studies that may aid in prevention, early detection, clarification of pathogenesis and effective treatment modalities for DILI.

\section{Supplementary Material}

Refer to Web version on PubMed Central for supplementary material.

\section{Acknowledgments}

Drs Bell, Vuppalanchi, Serrano, Fontana, Wang and Rochon have no conflicts of interest. Declaration of funding interests: Supported by 3 U01 DK065211-0751-ARRA to Naga Chalasani and the DILIN network is supported by the National Institute of Diabetes and Digestive and Kidney Diseases under the following cooperative agreements: 1U01DK065021, U01DK065193, 1U01DK065201, 1U01DK065193, 1U01DK065184, 1U01DK065211, 1U01DK065238 and 1U01DK065176.

\section{REFERENCES}

1. Navarro VJ, Senior JR. Drug-related hepatotoxicity. N Engl J Med. 2006; 354:731-9. [PubMed: 16481640]

2. Watkins PB, Seeff LB. Drug-induced liver injury: summary of a single topic clinical research conference. Hepatology. 2006; 43:618-31. [PubMed: 16496329]

3. Abboud G, Kaplowitz N. Drug-induced liver injury. Drug Saf. 2007; 30:277-94. [PubMed: 17408305]

4. Bonkovsky, HL.; Shedlofsky, SI.; Jones, DP., et al. Drug-induced liver injury. In: Boyer, TD.; Manns, MP.; Sanyal, A., editors. Zakim and Boyer's Hepatology - A Textbook of Liver Disease. 6th ed. Saunders-Elsevier; Philadelphia: 2011.

5. Ostapowicz G, Fontana RJ, Schiodt FV, et al. Results of a prospective study of acute liver failure at 17 tertiary care centers in the United States. Ann Intern Med. 2002; 137:947-54. [PubMed: 12484709]

6. Reuben A, Koch DG, Lee WM. Drug-induced acute liver failure: results of a U.S. multicenter, prospective study. Hepatology. 2010; 52:2065-76. [PubMed: 20949552]

7. Bjornsson E. Drug-induced liver injury in clinical practice. Aliment Pharmacol Ther. 2010; 32:3-13. [PubMed: 20374223]

8. Chalasani N, Bjornsson E. Risk factors for idiosyncratic drug-induced liver injury. Gastroenterology. 2010; 138:2246-59. [PubMed: 20394749]

9. Au JS, Navarro VJ, Rossi S. Drug-induced liver injury - its pathophysiology and evolving diagnostic tools. Aliment Pharmacol Ther. 2011; 34:11-20. [PubMed: 21539586]

10. Fontana RJ, Watkins PB, Bonkovsky HL, et al. Drug-Induced Liver Injury Network (DILIN) prospective study: rationale, design and conduct. Drug Saf. 2009; 32:55-68. [PubMed: 19132805]

11. Rockey DC, Seeff LB, Rochon J, et al. Causality assessment in drug-induced liver injury using a structured expert opinion process: comparison to the Roussel-Uclaf causality assessment method. Hepatology. 2010; 51:2117-26. [PubMed: 20512999]

12. Chalasani N, Fontana RJ, Bonkovsky HL, et al. Causes, clinical features, and outcomes from a prospective study of drug-induced liver injury in the United States. Gastroenterology. 2008; 135:1924-34. [PubMed: 18955056]

13. Vuppalanchi R, Hayashi PH, Chalasani N, et al. Duloxetine hepatotoxicity: a case-series from the drug-induced liver injury network. Aliment Pharmacol Ther. 2010; 32:1174-83. [PubMed: 20815829]

14. Orman ES, Conjeevaram HS, Vuppalanchi R, et al. Clinical and histopathologic features of fluoroquinolone-induced liver injury. Clin Gastroenterol Hepatol. 2011; 9:517-23. [PubMed: 21356330] 
15. Wang M, You J, Bemis KG, et al. Label-free mass spectrometry-based protein quantification technologies in proteomic analysis. Brief Funct Genomic Proteomic. 2008; 7:329-39. [PubMed: 18579615]

16. Bell LN, Theodorakis JL, Vuppalanchi R, et al. Serum proteomics and biomarker discovery across the spectrum of nonalcoholic fatty liver disease. Hepatology. 2010; 51:111-20. [PubMed: 19885878]

17. Bradford MM. A rapid and sensitive method for the quantitation of microgram quantities of protein utilizing the principle of protein-dye binding. Anal Biochem. 1976; 72:248-54. [PubMed: 942051]

18. Hale JE, Butler JP, Gelfanova V, et al. A simplified procedure for the reduction and alkylation of cysteine residues in proteins prior to proteolytic digestion and mass spectral analysis. Anal Biochem. 2004; 333:174-81. [PubMed: 15351294]

19. Higgs RE, Knierman MD, Gelfanova V, et al. Comprehensive label-free method for the relative quantification of proteins from biological samples. J Proteome Res. 2005; 4:1442-50. [PubMed: 16083298]

20. Craig R, Beavis RC. TANDEM: matching proteins with tandem mass spectra. Bioinformatics. 2004; 20:1466-7. [PubMed: 14976030]

21. Eng J, McCormack A, Yates RR. An approach to correlate tandem mass spectral data of peptides with amino acid sequences in a protein database. J Am Soc Mass Spectrom. 1994; 5:976-89.

22. Higgs RE, Knierman MD, Freeman AB, et al. Estimating the statistical significance of peptide identifications from shotgun proteomics experiments. J Proteome Res. 2007; 6:1758-67. [PubMed: 17397207]

23. Bolstad BM, Irizarry RA, Astrand M, et al. A comparison of normalization methods for high density oligonucleotide array data based on variance and bias. Bioinformatics. 2003; 19:185-93. [PubMed: 12538238]

24. Tujios S, Fontana RJ. Mechanisms of drug-induced liver injury: from bedside to bench. Nat Rev Gastroenterol Hepatol. 2011; 8:202-11. [PubMed: 21386809]

25. Kienhuis AS, Bessems JG, Pennings JL, et al. Application of toxicogenomics in hepatic systems toxicology for risk assessment: acetaminophen as a case study. Toxicol Appl Pharmacol. 2011; 250:96-107. [PubMed: 20970440]

26. Ellinger-Ziegelbauer H, Adler M, Amberg A, et al. The enhanced value of combining conventional and "omics" analyses in early assessment of drug-induced hepatobiliary injury. Toxicol Appl Pharmacol. 2011; 252:97-111. [PubMed: 20888850]

27. Lewis JA, Dennis WE, Hadix J, et al. Analysis of secreted proteins as an in vitro model for discovery of liver toxicity markers. J Proteome Res. 2010; 9:5794-802. [PubMed: 20822094]

28. Shimada T, Nakanishi T, Toyama A, et al. Potential implications for monitoring serum bile acid profiles in circulation with serum proteome for carbon tetrachloride-induced liver injury/ regeneration model in mice. J Proteome Res. 2010; 9:4490-500. [PubMed: 20583827]

29. Wang Y, Yang B, Wu C, et al. Plasma and liver proteomic analysis of 3Z-3-[(1H-pyrrol-2-yl)methylidene]-1-(1-piperidinylmethyl)-1,3-2H-indol-2-one-induced hepatotoxicity in Wistar rats. Proteomics. 2010; 10:2927-41. [PubMed: 20544730]

30. Andersson U, Lindberg J, Wang S, et al. A systems biology approach to understanding elevated serum alanine transaminase levels in a clinical trial with ximelagatran. Biomarkers. 2009; 14:57286. [PubMed: 19780643]

31. Jia N, Liu X, Wen J, et al. A proteomic method for analysis of CYP450s protein expression changes in carbon tetrachloride induced male rat liver microsomes. Toxicology. 2007; 237:1-11. [PubMed: 17606319]

32. Craig A, Sidaway J, Holmes E, et al. Systems toxicology: integrated genomic, proteomic and metabonomic analysis of methapyrilene induced hepatotoxicity in the rat. J Proteome Res. 2006; 5:1586-601. [PubMed: 16823966]

33. Merrick BA, Bruno ME, Madenspacher JH, et al. Alterations in the rat serum proteome during liver injury from acetaminophen exposure. J Pharmacol Exp Ther. 2006; 318:792-802. [PubMed: 16687475] 
34. Rodriguez-Ariza A, Lopez-Sanchez LM, Gonzalez R, et al. Altered protein expression and protein nitration pattern during d-galactosamine-induced cell death in human hepatocytes: a proteomic analysis. Liver Int. 2005; 25:1259-69. [PubMed: 16343079]

35. Amacher DE, Adler R, Herath A, et al. Use of proteomic methods to identify serum biomarkers associated with rat liver toxicity or hypertrophy. Clin Chem. 2005; 51:1796-803. [PubMed: 16099942]

36. Welch KD, Wen B, Goodlett DR, et al. Proteomic identification of potential susceptibility factors in drug-induced liver disease. Chem Res Toxicol. 2005; 18:924-33. [PubMed: 15962927]

37. Kleno TG, Kiehr B, Baunsgaard D, et al. Combination of 'omics' data to investigate the mechanism(s) of hydrazine-induced hepatotoxicity in rats and to identify potential biomarkers. Biomarkers. 2004; 9:116-38. [PubMed: 15370871]

38. O'Connell TM, Watkins PB. The application of metabonomics to predict drug-induced liver injury. Clin Pharmacol Ther. 2010; 88:394-9. [PubMed: 20668441]

39. Cui Y, Paules RS. Use of transcriptomics in understanding mechanisms of drug-induced toxicity. Pharmacogenomics. 2010; 11:573-85. [PubMed: 20350139]

40. Scott CR. The genetic tyrosinemias. Am J Med Genet C Semin Med Genet. 2006; 142C:121-6. [PubMed: 16602095]

41. Maniratanachote R, Shibata A, Kaneko S, et al. Detection of autoantibody to aldolase B in sera from patients with troglitazone-induced liver dysfunction. Toxicology. 2005; 216:15-23. [PubMed: 16115720]

42. Laverty HG, Antoine DJ, Benson C, et al. The potential of cytokines as safety biomarkers for druginduced liver injury. Eur J Clin Pharmacol. 2010; 66:961-76. [PubMed: 20694460]

43. Ferre N, Martinez-Clemente M, Lopez-Parra M, et al. Increased susceptibility to exacerbated liver injury in hypercholesterolemic ApoE-deficient mice: potential involvement of oxysterols. Am J Physiol Gastrointest Liver Physiol. 2009; 296:G553-62. [PubMed: 19136384] 


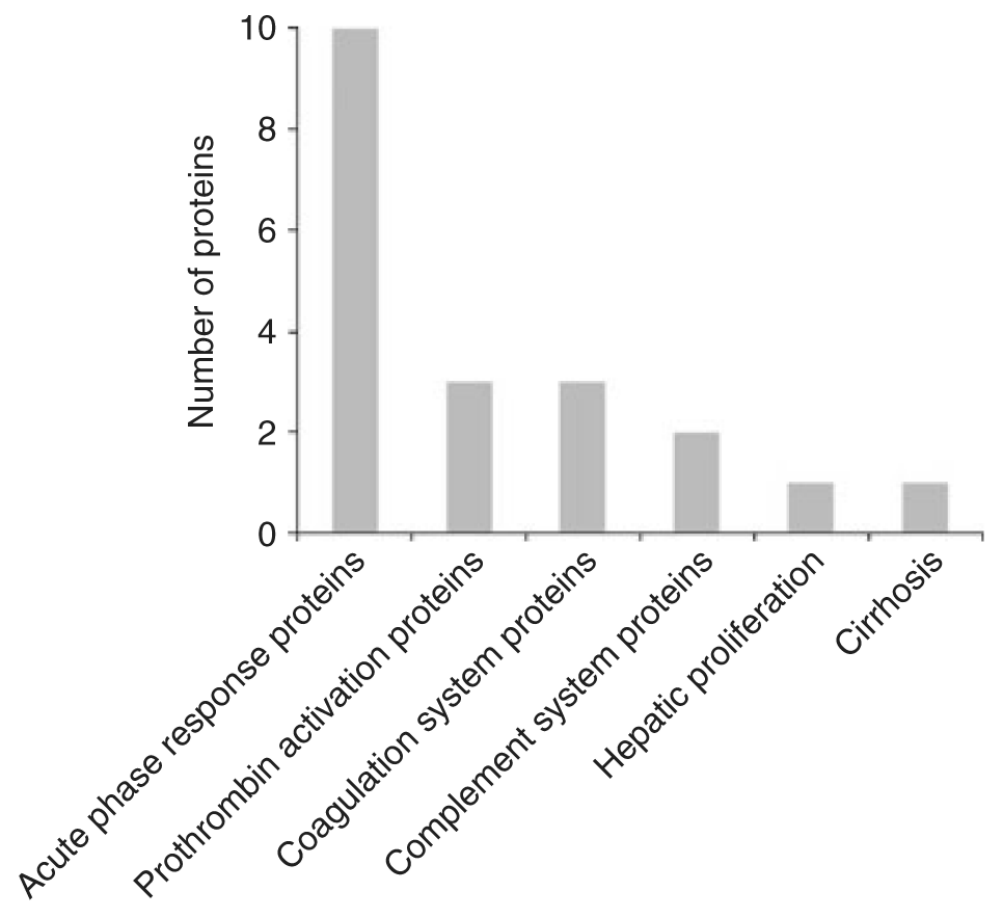

Figure 1.

Pathway analysis of priority 1 proteins with significant differential expression when comparing DILI patients with hepatocellular and cholestatic patterns of liver injury. Classification of the 25 priority 1 proteins with significant $(q<0.05)$ differential expression when comparing patients with hepatocellular and cholestatic DILI demonstrated involvement in inflammatory and immune system response pathways, activation of the coagulation cascade and included proteins previously implicated in liver proliferation and development of cirrhosis. 


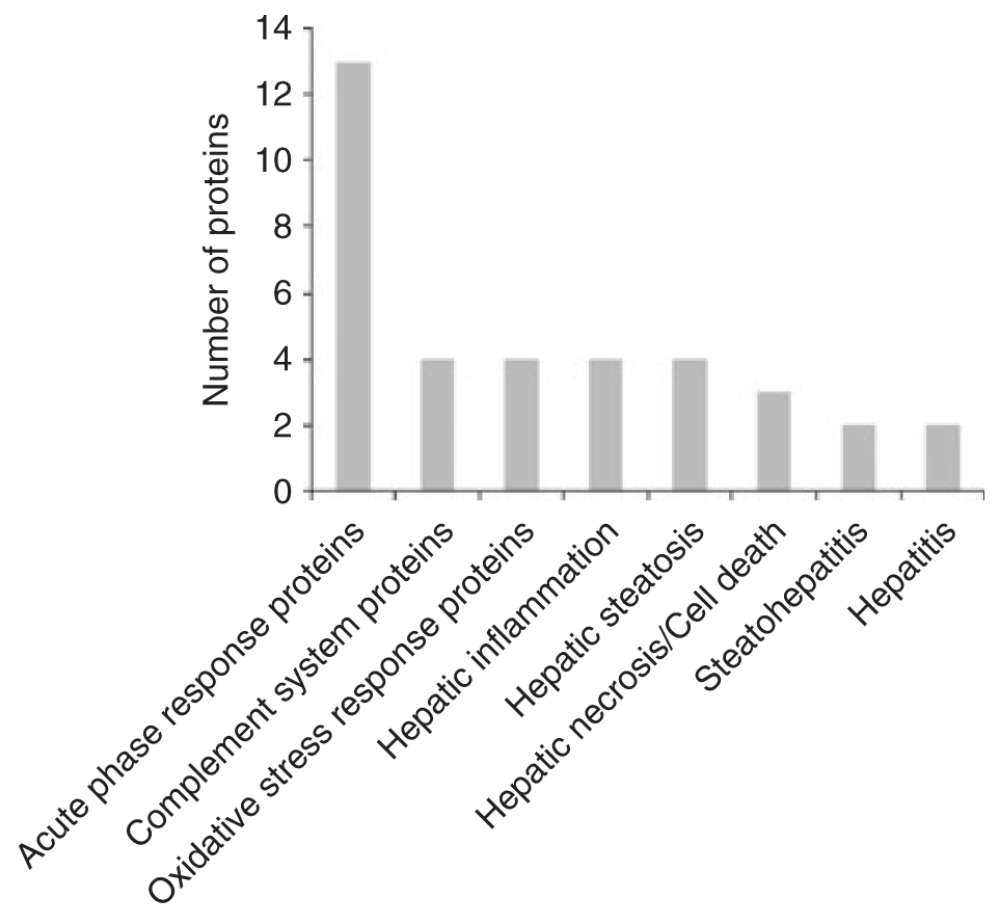

Figure 2.

Pathway analysis of priority 1 proteins with significant differential expression when comparing baseline and 6-month follow-up samples from patients with DILI included in the longitudinal analysis. Classification of the 53 priority 1 proteins with significant $(q<0.05)$ differential expression when comparing patients with DILI at baseline (within 14 days of DILI onset) and after a 6-month follow-up period revealed proteins with functions related to inflammation and oxidative stress, including those involved in liver steatosis/steatohepatitis/ hepatitis and hepatocyte necrosis/cell death. Expression of nearly all differentially expressed proteins returned to 'normal' expression levels throughout the 6-month follow-up period (using protein expression in the control group as a reference standard). 


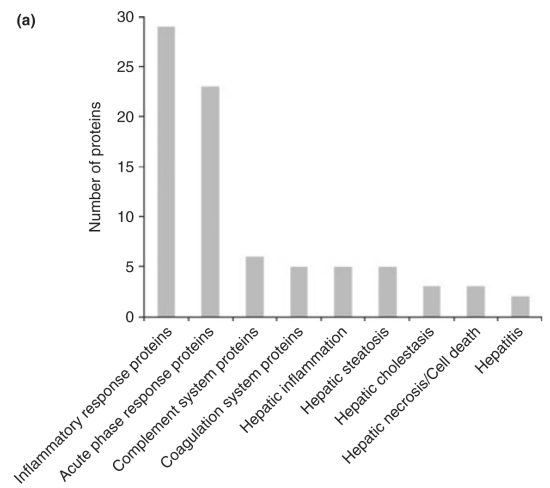

(b)

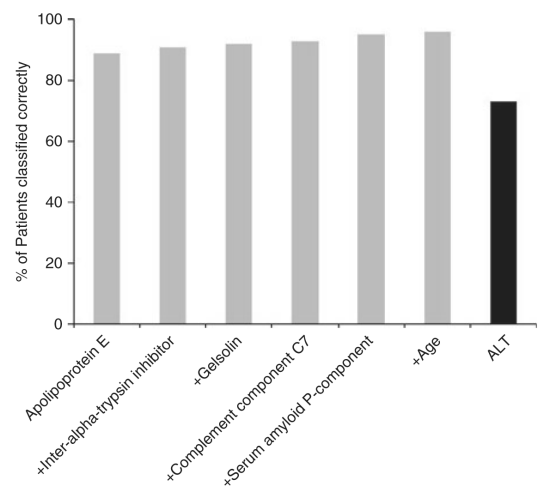

Figure 3.

Pathway analysis of priority 1 proteins differentially expressed between DILI patients and controls and identification of proteins with the greatest ability to differentiate patients with DILI vs. controls. Ingenuity Pathway Analysis software was used to classify the 92 priority 1 proteins with significant $(q<0.05)$ differential expression when comparing DILI patients and controls (Panel A), and pattern analysis showed involvement in many pathways previously implicated in the pathogenesis of DILI, including several directly related to hepatotoxicity (liver inflammation, steatosis, cholestasis, necrosis/cell death, and hepatitis). Diagnostic power of priority 1 proteins and clinical characteristics was explored by linear discriminant analysis and assessment of AUROC (Panel B; grey bars). Apolipoprotein E was identified as having the greatest power to differentiate DILI patients and controls (89\% of patients classified correctly; AUROC $=0.97$ ), and consideration of expression of several additional proteins and age increased the percentage of patients classified correctly to $96 \%$ and the AUROC to 0.99. The diagnostic utility of ALT alone (black bar) in differentiating patients from controls is also shown $(73 \%$ correct classification; AUROC $=0.99)$. 
Table 1

Clinical characteristics and liver biochemistries of all study participants

\begin{tabular}{|c|c|c|}
\hline & $\begin{array}{l}\text { DILI cohort } \\
n=74\end{array}$ & $\begin{array}{l}\text { Healthy } \\
\text { controls } \\
n=40\end{array}$ \\
\hline Age, mean \pm s.d. (years) & $47.8 \pm 18.3$ & $49.2 \pm 13.1$ \\
\hline Female $(\%)$ & 53 & 28 \\
\hline \multicolumn{3}{|l|}{ Self-reported race $(\%)$} \\
\hline White & 72 & 95 \\
\hline Black & 11 & 5 \\
\hline Others & 16 & 0 \\
\hline Unknown & 1 & 0 \\
\hline $\begin{array}{l}\text { Body mass index, } \\
\text { mean } \pm \text { s.d. }(\mathrm{kg} / \mathrm{m} 2)\end{array}$ & $27.0 \pm 6.6$ & $30.5 \pm 6.9$ \\
\hline Alcohol use (\%) & 39 & \\
\hline $\begin{array}{c}\text { Preexisting liver } \\
\text { disease }(\%)^{*}\end{array}$ & 8 & \\
\hline Prior drug allergies $(\%)$ & 50 & \\
\hline Diabetes mellitus (\%) & 34 & \\
\hline \multicolumn{3}{|c|}{ Liver biochemistries, mean \pm s.d. } \\
\hline ALT (U/L) & $1086 \pm 1409$ & $17.4 \pm 5.1$ \\
\hline AST (U/L) & $1028 \pm 1274$ & $24.3 \pm 4.9$ \\
\hline $\begin{array}{l}\text { Alkaline phosphatase } \\
\text { (U/L) }\end{array}$ & $325.3 \pm 470.1$ & $63.2 \pm 14.0$ \\
\hline Total bilirubin $(\mathrm{mg} / \mathrm{dL})$ & $8.0 \pm 7.6$ & $0.6 \pm 0.2$ \\
\hline INR & $1.8 \pm 1.2$ & \\
\hline $\begin{array}{l}\text { Absolute eosinophils/iL } \\
\quad(\text { mean } \pm \text { s.d. })\end{array}$ & $172.3 \pm 240.2$ & \\
\hline \multicolumn{3}{|l|}{ Pattern of liver injury (\%) } \\
\hline Hepatocellular & 61 & \\
\hline Cholestatic & 20 & \\
\hline Mixed & 15 & \\
\hline Unknown & 4 & \\
\hline \multicolumn{3}{|l|}{ Severity of liver injury (\%) } \\
\hline Mild & 12 & \\
\hline Moderate & 47 & \\
\hline Severe/fatal & 26 & \\
\hline Unknown & 15 & \\
\hline \multicolumn{3}{|l|}{ Causality score $(\%)$} \\
\hline Definite & 23 & \\
\hline Very likely & 36 & \\
\hline Probable & 11 & \\
\hline
\end{tabular}




\begin{tabular}{|c|c|c|}
\hline & $\begin{array}{l}\text { DILI cohort } \\
n=74\end{array}$ & $\begin{array}{l}\text { Healthy } \\
\text { controls } \\
n=40\end{array}$ \\
\hline Possible & 15 & \\
\hline Unknown & 15 & \\
\hline \multicolumn{3}{|l|}{ Implicated agents (\%) } \\
\hline Single prescribed agent & 57 & \\
\hline Single dietary agent & 5 & \\
\hline $\begin{array}{l}\text { Multiple prescribed } \\
\text { agents }\end{array}$ & 35 & \\
\hline Unknown & 3 & \\
\hline Chronic DILI (\%) & 5 & \\
\hline Liver-related mortality (\%) & 5 & \\
\hline Liver transplantation (\%) & 0 & \\
\hline
\end{tabular}

ALT, alanine aminotransferase; AST, aspartate aminotransferase; DILI, drug-induced liver injury; INR, international normalised ratio; s.d., standard deviation.

Pre-existing liver conditions included hepatitis C, hepatitis B, alcoholic liver disease and nonalcoholic fatty liver disease. 
Table 2

Implicated causative agents

\begin{tabular}{|c|c|}
\hline Single agent & $\begin{array}{l}\text { Multiple agents } \\
(n=1 \text { case each })\end{array}$ \\
\hline Isoniazid $(n=5)$ & $\begin{array}{l}\text { Moxifloxacin + ciprofloxacin } \\
+ \text { amoxicillin/clavulanate }\end{array}$ \\
\hline Herbal preparation $(n=5)$ & $\begin{array}{l}\text { Pregabalin + simvastatin } \\
\quad+\text { mercaptopurine }\end{array}$ \\
\hline $\begin{array}{l}\text { Amoxicillin/ } \\
\text { clavulanate }(n=3)\end{array}$ & $\begin{array}{l}\text { Darunavir } \\
\quad+\text { abacavir/lamivudine } \\
\quad \text { + didanosine }\end{array}$ \\
\hline Nitrofurantoin $(n=3)$ & $\begin{array}{l}\text { Trimethoprim- } \\
\text { sulfamethoxazole } \\
\text { + orlistat }\end{array}$ \\
\hline Methyldopa $(n=2)$ & $\begin{array}{l}\text { Metoprolol + diltiazem } \\
\quad+\text { alprazolam }\end{array}$ \\
\hline Minocycline $(n=2)$ & $\begin{array}{l}\text { Isoflurane + lorazepam } \\
\quad+\text { clindamycin }\end{array}$ \\
\hline $\begin{array}{l}\text { Trimethoprim- } \\
\quad \text { sulfamethoxazole }(n=2)\end{array}$ & $\begin{array}{l}\text { Trimethoprim- } \\
\text { sulfamethoxazole }+ \\
\text { tetracycline }\end{array}$ \\
\hline Amiodarone $(n=1)$ & $\begin{array}{l}\text { Phenytoin + levofloxacin } \\
\quad+\text { phenobarbital }\end{array}$ \\
\hline Amlodipine $(n=1)$ & Isoniazid + rifampicin \\
\hline Anabolic steroid $(n=1)$ & Ciprofloxacin + metronidazole \\
\hline $\begin{array}{l}\text { Antithymocite } \\
\text { immunoglobulin }(n=1)\end{array}$ & Amitriptyline + nicotinic acid \\
\hline Atorvastatin $(n=1)$ & Allopurinol + rosiglitazone \\
\hline Atripla $(n=1)$ & Vincristine + asparaginase \\
\hline Azathioprine $(n=1)$ & $\begin{array}{l}\text { Ceftriaxone + ampicillin/ } \\
\text { sulbactam + fluconazole }\end{array}$ \\
\hline Azithromycin $(n=1)$ & Flavocoxid + pregabalin \\
\hline Bortezomib $(n=1)$ & $\begin{array}{l}\text { Amoxicillin/clavulanate } \\
+ \text { valproic acid + amiodarone }\end{array}$ \\
\hline Chlorzoxazone $(n=1)$ & Methyldopa + labetalol \\
\hline $\begin{array}{l}\text { Drospirenone/ } \\
\quad \text { ethinylestradiol }(n=1)\end{array}$ & $\begin{array}{l}\text { Dicloxacillin }+ \\
\text { amoxicillin/clavulanate }\end{array}$ \\
\hline Duloxetine $(n=1)$ & Nicotinic acid + neomycin \\
\hline Fenofibrate $(n=1)$ & Lamotrigine + ziprasidone \\
\hline Investigational drug $(n=1)$ & Lamotrigine + valproic acid \\
\hline Lamotrigine $(n=1)$ & Disulfiram + lisinopril \\
\hline Nicotinic Acid $(n=1)$ & $\begin{array}{l}\text { Allopurinol + fluconazole } \\
\text { + cyclophosphamide }\end{array}$ \\
\hline Octreotide $(n=1)$ & $\begin{array}{l}\text { Carbamazapine + bactrim } \\
+ \text { lisinopril }\end{array}$ \\
\hline Oxacillin $(n=1)$ & Metformin + fenofibrate \\
\hline Phenylpropanolamine $(n=1)$ & Voriconazole + fluconazole \\
\hline Phenytoin $(n=1)$ & \\
\hline
\end{tabular}




\begin{tabular}{ll}
\hline Single agent & $\begin{array}{l}\text { Multiple agents } \\
(\boldsymbol{n}=\mathbf{1} \text { case each })\end{array}$ \\
\hline Pregabalin $(n=1)$ & \\
\hline Rifabutin $(n=1)$ & \\
\hline Sertraline $(n=1)$ & Simvastatin $(n=1)$ \\
\hline Telithromycin $(n=1)$ \\
\hline Valaciclovir $(n=1)$ \\
\hline
\end{tabular}




\section{Table 3}

Correlative analyses of priority 1 protein expression and liver biochemistries in the DILI cohort

\begin{tabular}{|c|c|c|c|c|c|c|}
\hline \multirow{2}{*}{$\begin{array}{l}\text { Liver } \\
\text { biochemistry }\end{array}$} & \multicolumn{3}{|l|}{$\underline{\text { Positive correlates }}$} & \multicolumn{3}{|l|}{$\underline{\text { Negative correlates }}$} \\
\hline & Protein & rho $(95 \% \mathrm{CI})$ & $P$-value & Protein & rho $(95 \% \mathrm{CI})$ & $P$-value \\
\hline \multirow[t]{4}{*}{ ALT } & alpha-1-antitrypsin (isoform 1) & $0.250(0.018,0.457)$ & 0.036 & & & \\
\hline & PR02275 & $0.246(0.013,0.453)$ & 0.039 & & & \\
\hline & Fructose-bisphosphate aldolase $\mathrm{B}{ }^{*}$ & $0.391(0.173,0.572)$ & 0.001 & & & \\
\hline & Fumarylacetoacetase & $0.237(0.003,0.445)$ & 0.047 & & & \\
\hline \multirow[t]{11}{*}{ AST } & alpha-1-antitrypsin (isoform 1) & $0.329(0.107,0.520)$ & 0.005 & Transthyretin & $-0.249(-0.453,-0.020)$ & 0.034 \\
\hline & PR02275 & $0.334(0.112,0.524)$ & 0.004 & & & \\
\hline & C-reactive protein (isoform 1) & $0.300(0.075,0.496)$ & 0.0 & & & \\
\hline & Leucine-rich alpha-2-glycoprotein & $0.239(0.010,0.445)$ & 0.041 & & & \\
\hline & Fructose-bisphosphate aldolase B ${ }^{*}$ & $0.523(0.333,0.672)$ & $<0.001$ & & & \\
\hline & Fumarylacetoacetase & $0.389(0.174,0.568)$ & 0.001 & & & \\
\hline & Serpin A11 & $0.302(0.078,0.498)$ & 0.009 & & & \\
\hline & $\begin{array}{l}\text { DNA-directed RNA polymerase I } \\
\text { subunit RPA1 }\end{array}$ & $0.290(0.064,0.487)$ & 0.013 & & & \\
\hline & Obscurin (isoform 1) & $0.335(0.114,0.525)$ & 0.004 & & & \\
\hline & alpha-skeletal muscle actin & $0.252(0.023,0.456)$ & 0.032 & & & \\
\hline & Aortic smooth muscle actin & $0.259(0.030,0.461)$ & 0.027 & & & \\
\hline \multirow[t]{3}{*}{$\begin{array}{l}\text { Alkaline } \\
\text { Phosphatase }\end{array}$} & $\begin{array}{l}\text { Uncharacterized protein C22orf30 } \\
\text { (isoform 4) }\end{array}$ & $0.342(0.120,0.532)$ & 0.003 & Fumarylacetoacetase & $-0.240(-0.446,-0.008)$ & 0.043 \\
\hline & Serum amyloid A2 (isoform a) & $0.238(0.006,0.445)$ & 0.044 & & & \\
\hline & Apolipoprotein C-III ${ }^{*}$ & $0.322(0.098,0.515)$ & 0.006 & & & \\
\hline \multirow[t]{12}{*}{ Total Bilirubin } & Apolipoprotein E & $0.280(0.051,0.480)$ & 0.017 & & & \\
\hline & Polymeric immunoglobulin receptor & $0.391(0.175,0.571)$ & 0.001 & Apolipoprotein A-II ${ }^{*}$ & $-0.503(-0.658,-0.308)$ & $<0.001$ \\
\hline & von Willebrand factor & $0.325(0.101,0.518)$ & 0.005 & Apolipoprotein A-I & $-0.391(-0.571,-0.176)$ & 0.001 \\
\hline & Aminoacylase-1 & $0.240(0.008,0.446)$ & 0.043 & $\begin{array}{l}\text { G-protein coupled } \\
\text { receptor } 98 \text { (isoform 1) }\end{array}$ & $-0.488(-0.647,-0.289)$ & $<0.001$ \\
\hline & Fructose-bisphosphate aldolase A & $0.261(0.032,0.465)$ & 0.027 & Paraoxonase/arylesterase 1 & $-0.282(-0.482,-0.053)$ & 0.017 \\
\hline & Complement component C7 & $0.249(0.019,0.455)$ & 0.035 & Hemopexin ${ }^{*}$ & $-0.494(-0.651,-0.296)$ & $<0.001$ \\
\hline & $\begin{array}{l}\text { Complement } \mathrm{C} 1 \mathrm{q} \text { subcomponent } \\
\quad \text { (subunit } \mathrm{A})\end{array}$ & $0.308(0.082,0.504)$ & 0.009 & Paraoxonase/lactonase 3 & $-0.251(-0.456,-0.021)$ & 0.033 \\
\hline & Complement C2 (fragment) & $0.389(0.172,0.569)$ & 0.001 & $\begin{array}{l}\text { Versican core protein } \\
\text { (isoform Vint) }\end{array}$ & $-0.255(-0.460,-0.025)$ & 0.031 \\
\hline & $\begin{array}{l}\text { Extracellular matrix protein } 1 \\
\quad \text { (isoform } 1)\end{array}$ & $0.314(0.089,0.509)$ & 0.007 & $\begin{array}{l}\text { E3 SUMO-protein ligase } \\
\text { RanBP2 }\end{array}$ & $-0.265(-0.468,-0.036)$ & 0.024 \\
\hline & Obscurin (isoform 1) & $0.310(0.084,0.505)$ & 0.008 & $\begin{array}{l}\text { Haptoglobin-related } \\
\text { protein (isoform 1) }\end{array}$ & $-0.237(-0.444,-0.005)$ & 0.046 \\
\hline & Adiponectin & $0.312(0.086,0.507)$ & 0.008 & Haptoglobin & $-0.238(-0.445,-0.007)$ & 0.044 \\
\hline & Tetranectin & $0.252(0.022,0.457)$ & 0.033 & & & \\
\hline
\end{tabular}




\begin{tabular}{|c|c|c|c|c|c|c|}
\hline Liver & $\underline{\text { Positive correlates }}$ & & & Negative correlates & & \\
\hline & Protein & rho $(95 \%$ CI $)$ & $P$-value & Protein & rho $(95 \% \mathrm{CI})$ & $P$-value \\
\hline & $\begin{array}{l}\text { Uncharacterized protein } \\
\text { DKFZp686C02220 (fragment) }\end{array}$ & $0.345(0.123,0.534)$ & 0.003 & & & \\
\hline
\end{tabular}

ALT, alanine aminotransferase; AST, aspartate aminotransferase; CI, confidence interval; rho, Pearson's correlation coefficient. Independent predictor upon multivariate regression analysis. 


\section{Table 4}

Clinical characteristics and liver biochemistries of study participants included in the longitudinal analysis

\begin{tabular}{|c|c|}
\hline & $\begin{array}{l}\text { DILI Cohort } \\
\quad(n=21)\end{array}$ \\
\hline Age, mean \pm s.d. (years) & $52.1 \pm 15.1$ \\
\hline Female $(\%)$ & 48 \\
\hline \multicolumn{2}{|l|}{ Self-reported race $(\%)$} \\
\hline White & 67 \\
\hline Black & 14 \\
\hline Others & 19 \\
\hline Unknown & 0 \\
\hline Body mass index, mean \pm s.d. $\left(\mathrm{kg} / \mathrm{m}^{2}\right)$ & $27.5 \pm 7.7$ \\
\hline Alcohol use (\%) & 52 \\
\hline Preexisting liver disease $(\%)$ & 14 \\
\hline Prior drug allergies $(\%)$ & 48 \\
\hline Diabetes mellitus (\%) & 43 \\
\hline \multicolumn{2}{|l|}{ Liver biochemistries, mean \pm s.d. } \\
\hline \multicolumn{2}{|l|}{ ALT (U/L) } \\
\hline Baseline & $1325 \pm 2139$ \\
\hline 6-month visit & $36.1 \pm 16.5$ \\
\hline \multicolumn{2}{|l|}{$\operatorname{AST}(\mathrm{U} / \mathrm{L})$} \\
\hline Baseline & $1141 \pm 1696$ \\
\hline 6-month visit & $32.6 \pm 11.4$ \\
\hline \multicolumn{2}{|l|}{ Alkaline phosphatase (U/L) } \\
\hline Baseline & $219.9 \pm 161.0$ \\
\hline 6-month visit & $87.2 \pm 31.2$ \\
\hline \multicolumn{2}{|l|}{ Total bilirubin (mg/dL) } \\
\hline Baseline & $9.8 \pm 9.0$ \\
\hline 6-month visit & $0.9 \pm 0.7$ \\
\hline \multicolumn{2}{|l|}{ INR } \\
\hline Baseline & $1.9 \pm 1.0$ \\
\hline 6-month visit & $1.1 \pm 0.5$ \\
\hline \multicolumn{2}{|l|}{ Absolute eosinophils $/ \mu \mathrm{L}$ (mean \pm s.d.) } \\
\hline Baseline & $129.7 \pm 132.6$ \\
\hline 6-month visit & $122.2 \pm 115.5$ \\
\hline \multicolumn{2}{|l|}{ Pattern of liver injury (\%) } \\
\hline Hepatocellular & 76 \\
\hline Cholestatic & 19 \\
\hline Mixed & 5 \\
\hline Unknown & 0 \\
\hline
\end{tabular}




\begin{tabular}{lc}
\hline & $\begin{array}{c}\text { DILI Cohort } \\
(\boldsymbol{n}=\mathbf{2 1})\end{array}$ \\
\hline Severity of liver injury (\%) & 10 \\
\hline Mild & 38 \\
\hline Moderate & 29 \\
\hline Severe/fatal & 24 \\
\hline Unknown & \\
\hline Causality score (\%) & 14 \\
\hline Definite & 43 \\
\hline Very likely & 5 \\
\hline Probable & 14 \\
\hline Possible & 24 \\
\hline Unknown & \\
\hline Implicated agents (\%) & 57 \\
\hline Single prescribed agent & 10 \\
\hline Single dietary agent & 33 \\
\hline Multiple prescribed agents & 0 \\
\hline Unknown & 0 \\
\hline Chronic DILI (\%) & 0 \\
\hline Liver-related mortality (\%) & 0 \\
\hline Liver transplantation (\%) & \\
\hline
\end{tabular}

DILI, drug-induced liver injury; s.d., standard deviation; ALT, alanine aminotransferase; AST, aspartate aminotransferase; INR, international normalised ratio. 